\title{
ОСОБЕННОСТИ ВЗАИМОСВЯЗИ МОНЕТАРНОГО ПОВЕДЕНИЯ И КОМПОНЕНТОВ ЖИЗНЕСТОЙКОСТИ МОЛОДЕЖИ ${ }^{1}$
}

\section{FEATURES OF THE RELATIONSHIP BETWEEN MONETARY BEHAVIOR AND COMPONENTS OF YOUTH RESILIENCE \\ N. Kozlova \\ A. Larionova V. Obukhovskaya}

Summary: The subject of the study is the features of monetary behavior of young people (avoiding money, money as a status, money worship, vigilance about money) in relation to the components of resilience (involvement, control, acceptance/readiness for risk, the General indicator of resilience). The study of the relationship between monetary behavior and the resilience of young people is an urgent problem that reflects the ability to cope with life circumstances, the desire to overcome difficulties in the financial sphere. As a result of the study, it was found that young people who are characterized by an attitude to money as a status, are more prone to stressful situations and a critical attitude to monetary interactions. Young people who treat money as a savings resource are more prudent and cautious in financial matters. Comparative analysis revealed that the inconsistency in monetary behavior-the desire to accumulate money and risky behavior in relation to money-is more characteristic of the female part of the sample.

Keywords: monetary behavior, hardiness, monetary attitudes, attitudes of the monetary behavior, risk-readiness, money, young people.
Козлова Наталья Викторовна

Д.nсх.н., профессор, ФГАОУВО «Национальный исследовательский Томский государственный университет», г. Томск akme_2003@mail.ru

Ларионова Анастасия Вячеславовна

К.nсх.н., дочент, ФГАОУ ВО «Национальный исследовательский Томский государственный университет»; г. Томск

vktusur@mail.ru

Обуховская Виктория Борисовна

К.nсх.н., старший преподаватель, «Национальный исследовательский Томский государственный университет»; "Сибирский государственный медицинский университет» Министерства здравоохранения Российской Федерации, г. Томск diada1991@gmail.com

Аннотация: Предметом исследования являются особенности монетарного поведения молодежи (избегание денег, деньги как статус, поклонение деньгам, бдительность относительно денег) во взаимосвязи ( компонентами жизнестойкости (вовлеченность, контроль, принятие/готовность к риску, общий показатель жизнестойкости). Изучение особенностей взаимосвязи монетарного поведения и жизнестойкости молодежи является актуальной проблемой, которая отражает способность справляться с жизненными обстоятельствами, стремление к преодолению трудностей в финансовой сфере. В результате исследования было выявлено, что молодым людям, для которых характерно отношение к деньгам как к статусу, в большей мере свойственна подверженность стрессовым ситуациям и критическое отношение к денежным взаимодействиям. Молодые люди, которые относятся к деньгам как накопительному ресурсу, более предусмотрительны и осторожны в финансовых вопросах. Сравнительный анализ позволил обнаружить, что противоречивость в монетарном поведении - стремление к накоплению денег и рисковое поведение в отношение денег - больше свойственна женской части выборки.

Ключевые слова: монетарное поведение, жизнестойкость, монетарные аттитюды, деньги, готовность к риску, молодежь.

и ограничения, используя современные инструменты экономики, формирование эффективного монетарного поведения в целом является важной задачей региона и страны [5].

На сегодняшний день изучение монетарного (денежного) поведения представляет собой развивающуюся и востребованную в теоретическом и практическом плане 
отрасль психологии, экономики и социологии [15]. Интерес к данной тематике связан с переходом к смешанной экономике, несоответствием между материальными возможностями, ментальными особенностями и содержанием современной экономической жизни, невысоком уровне финансовой грамотности и т.д. [2]. Системообразующим фактором монетарного поведения человека является его отношение к деньгам [9], обусловленное его установками, позицией по отношению к деньгам, то есть денежными установками как личностными переменными людей, их психологическими особенностями. А.А. Письменова в своих исследованиях рассматривает монетарное поведение как «конативный компонент ценностно-смысловых отношений личности к деньгам, которое проявляется в совокупности действий с деньгами или потенциальной готовности к этим действиям» [12]. Монетарное поведение является структурной составляющей экономического поведения, которое рассматривается как специфический компонент отношений человека к деньгам [7, 12, 13], характеризующийся индивидуальным, субъективно-оценочным, избирательным подходом к обращению с деньгами, экономической идентичностью и экономическим сознанием.

Психологические факторы монетарного поведения указывают на различные адаптационные возможности человека и предусматривают воздействие на личностные переменные человека. В социально-психологическом исследовании С.Т. Джанерьян, А.А. Письменова рассматривали монетарное поведение во взаимосвязи с такими особенностями личности, как система ценностей, самосознание и волевые качества. Было установлено, что монетарное поведение связано с решительностью, самостоятельностью, ответственностью, целеустремленностью и самооценкой [6]. Результаты исследования взаимосвязи монетарного поведения и личностных особенностей способствовали пониманию детерминантов экономического благополучия личности и типологий отношения к деньгам, а изучение монетарного поведения во взаимосвязи с жизнестойкостью человека с учетом склонности и готовности к риску в условиях неопределенности позволит прояснить особенности поведения человека в трудных жизненных ситуациях (например, экономический кризис, социальные катаклизмы и т.п.). С.А. Богомаз и Д.Ю. Баланев отмечают, что в стрессовых ситуация жизнестойкость напрямую влияет на успешность человека в разных сферах деятельности, его стратегии справляться с возникшими трудностями, а уровень развития компонентов жизнестойкости характеризует способность человека сохранять внутреннюю сбалансированность, не снижая успешность своей деятельности, находить и использовать новые возможности, обеспечивающие его продвижение к намеченным целям [3].

Жизнестойкость рассматривается в контексте таких психологических категорий как психическое здо- ровье, стрессоустойчивость, эмоциональная стабильность, совладание, копинг-стратегии, адаптивность. В зарубежных исследованиях проблема жизнестойкости изучается, в основном, в условиях риска нарушения безопасности, который является значимым фактором, влияющим на психическое здоровье человека, пребывающего в небезопасных условиях. С. Мадди жизнестойкость (hardiness) определяет как внутренний ресурс, который препятствует возникновению внутреннего напряжения в стрессовых ситуациях, а также способствует совладанию со стрессом, позволяя превращать стрессовые ситуации в новые возможности личностного развития $[17,18]$. В эту структуру входят установки включенности (участие в социальном взаимодействии, постоянный контакт с окружающими, что задает позиция сотрудничества), контроля (стремление влиять на жизненные события в противовес ощущению беспомощности, что задает ценность надежности) и вызова (принятие жизненного риска в противовес безопасности и снижение напряжения, что порождает ценность творчества) [18]. Жизнестойкость, как базовая характеристика, позволяет опосредовать негативные стрессовые факторы посредством убеждений личности о возможности совладания с жизненными обстоятельствами, способности преодолеть трудности, которые рассматриваются как условие развития личностного потенциала [4, 10]. Анализ исследований, посвященных монетарному поведению и компонентам жизнестойкости, показал, что проблема выявления особенностей монетарного поведения и жизнестойкости молодежи требует совмещения подходов, разрабатываемых в социально-психологических науках, что обусловлено современной научной тенденцией к образованию новых, основанных на синтезе научных трендов с ранее сформировавшимися подходами.

В основу исследования, результаты которого представлены в данной статье, легло предположение, что для молодежи с выраженными компонентами жизнестойкости свойственны более эффективные стратегии монетарного поведения. Цель исследования - выявление особенностей монетарного поведения молодежи во взаимосвязи с компонентами жизнестойкости.

\section{Материалы и методы исследования}

В исследовании приняло участие 235 человек, возраст респондентов - от 17 до 35 лет (средний возраст 26,5 5 лет). Из них 146 человек - женского пола, 88 мужского, 1 - не указал свой пол. Высшее образование имеют 148 респондентов, неоконченное высшее - 35, среднее специальное - 19, среднее - 17, не указали уровень образования - 16.

Для выявления особенностей монетарного поведения и компонентов жизнестойкости использовались следующие методики: 
1. Опросник «Шкала монетарных аттитюдов» Б. Клонц и Т. Клонц (2011) [17] в адаптации Д.А. Баязитовой и Т.А. Лапшовой (2017) [1], предназначенный для изучения денежных установок личности. Методика включает в себя 4 шкалы: 7 Избегание денег (money avoidance), Деньги как статус (money status), Поклонение деньгам (money worship), Бдительность относительно денег (money vigilance).

2. Опросник «Тест жизнестойкости» С. Мадди (1994) [18] в адаптация Осина Е.Н., Рассказовой Е.И. (2013) [12]. Методика содержит 4 шкалы: Вовлеченность, Контроль, Принятие риска и Общий показатель жизнестойкости.

3. «Диагностика уровня личностной готовности к риску» («РSК» А.М. Шуберта, 1999) [19] а адаптации Ильина Е.П. (2012) [8], позволяющая оценить степень готовности к риску. Степень готовности оценивается по пятибалльной шкале (от полного согласия до полного несогласия).

4. «Шкала поиска ощущений» М. Цуккермана (1964) [15], направленная на исследование личностных факторов, лежащих в основе склонности к риску. Методика состоит из одной шкалы и предназначена для изучения жажду острых ощущений в качестве характеристики, лежащей в основе склонности к риску.

Математико-статистическая обработка данных производилась с помощью программного пакета Statistica 10. Для достижения цели исследования использовались статистические методы: методы описательной статистики, коэффициент ранговой корреляции Спирмена и критерий значимости Манна-Уитни.

\section{Результаты исследования и их обсужление}

На первом этапе осуществлялась оценка степени выраженности монетарного поведения - показателей денежных установок, склонности к риску, готовности к риску, и жизнестойкости с помощью методов описательной статистики по 10 показателям (таблица 1).

Результаты описательной статистики и анализ средних, представленные в таблице 1, указывают, что показатели соответствуют нормативным значениям шкалам методик.

Нормативные значения по шкалам «Избегание денег» $(M=2,16)$, «Деньги как статус» $(M=2,43)$, «Поклонение деньгам» $(M=3,46)$, «Бдительность относительно денег» $(M=3,44)$, свидетельствуют о том, что респонденты демонстрируют критическое отношение к денежным взаимодействиям и финансовым институтам, неготовность к чрезмерным тратам и рисковым вложениям средств, отсутствие склонности к расстройствам в сфере финансового поведения. Молодые люди не склонны разделять людей исходя из их экономического статуса и осторожны в манипуляциях собственными накоплениями.

Выявлены нормативные показатели по шкале «Вовлеченность» $(M=19,05)$, «Контроль» $(M=13,96)$ и «Принятие риска» $(M=10,41)$, то есть для молодых людей характерна заинтересованность в выполняемой деятельности, получение определенного удовольствия от неё и ощущение возможности влияния на результат даже в случае отсутствия гарантий успеха, неудачи же воспринимаются как возможность развития через приобретение нового опыта. Совокупность данных компонентов $(M=43,44)$ позволяет молодежи сохранять оптимальный уровень работоспособности в стрессогенных условиях.

Наблюдается умеренная готовность к риску, особенно в пределах неопределенности и ситуаций, требующих нарушения норм или правил (для шкалы «Личностная готовность к риску» $M=-2,36)$. Респонденты проявляют

Таблица 1.

Описательная статистика показателей монетарного поведения и компонентов жизнестойкости

\begin{tabular}{|l|c|c|c|c|c|}
\multicolumn{1}{|c|}{ Показатели методик } & Количество & Среднее & Ст. отклонение & Минимум & Максимум \\
\hline «Избегание денег» & 234 & 2,16 & 0,7 & 1 & 4,5 \\
\hline «Деньги как статус» & 234 & 2,43 & 0,76 & 1 & 4,57 \\
\hline «Поклонение деньгам» & 233 & 3,46 & 0,91 & 1,17 & 6 \\
\hline «Обеспокоенность деньгами» & 233 & 3,44 & 0,92 & 1 & 5,67 \\
\hline «Личностная готовность к риску» & 235 & $-2,36$ & 15,75 & -41 & 40 \\
\hline «Поиск ощущений» & 234 & 8,03 & 3,2 & 0 & 15 \\
\hline «0бщий показатель жизнестойкости» & 235 & 43,44 & 13,67 & 0 & 69 \\
\hline «Вовлеченность» & 235 & 19,05 & 6,46 & 0 & 30 \\
\hline «Контроль» & 235 & 13,98 & 4,69 & 0 & 24 \\
\hline «Принятие риска» & 235 & 10,41 & 3,65 & 0 & 20 \\
\hline
\end{tabular}


Корреляционный анализ между показателями методики «Шкала монетарных аттитюдов», «Тест жизнестойкости», «Диагностика уровня личностной готовности к риску», «Шкала поиска ощущений»

\begin{tabular}{|l|c|c|c|}
\multicolumn{1}{|c|}{ Показатели методик } & Шкала деньги как статус & Шкала обеспокоенность деньгами & $\begin{array}{c}\text { Диагностика уровня личностной } \\
\text { готовности к риску }\end{array}$ \\
\hline «0бщий показатель жизнестойкости» & $-0,26^{*}$ & $-0,11$ & 0,13 \\
\hline «Вовлеченность» & $-0,22^{*}$ & $-0,06$ & 0,1 \\
\hline «Контроль» & $-0,28^{*}$ & $-0,13$ & 0,19 \\
\hline «Принятие риска» & $-0,24^{*}$ & $-0,15$ & 0,15 \\
\hline «Личностная готовность к риску» & $-0,06$ & $-0,29^{*}$ & 1 \\
\hline «Поиск ощущений» & $-0,08$ & $-0,28^{*}$ & $0,48^{*}$ \\
\hline
\end{tabular}

* в таблице представлены значения с уровнем значимости $p<0,01, N=235$

как наличие готовности к реализации рискованного поведения, так и чрезмерную тревожность, осторожность. Это подтверждается результатами исследования по шка-

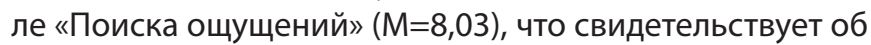
открытости респондентов новому опыту, при этом рассудительности и умении контролировать собственные потребности.

На следующем этапе анализа данных был проведен корреляционный анализ с использованием коэффициента Спирмена (r-Спирмена, rs) с целью выявления взаимосвязей между шкалами методики «Шкала монетарных аттитюдов» и компонентами жизнестойкости молодежи (табл. 2).

Результаты, представленные в таблице 2, демонстрируют взаимосвязь между показателями «Шкала деньги как статус» со шкалами «Общий показатель жизнестойкости» $(r s=-0,26)$, «Вовлеченность» $(r s=-0,22)$, «Контроль» $(r s=-0,28)$, «Принятие риска» (rs=-0,24). Полученные взаимосвязи свидетельствуют о том, что отношение к деньгам как к социально-экономическому статусу, показателю положения человека в обществе взаимосвязано с внутренним напряжением в стрессовых ситуациях, с ощущением себя не вовлеченным в жизненные события, с чувством беспомощности, с потребностью в надежных гарантий успеха в деятельности, то есть для молодежи финансовый статус и наличие материального благополучия необходимо для ощущения уверенности и безопасности.
Обратная взаимосвязь между показателями «Шкала обеспокоенность деньгами» со шкалами «Диагностика уровня личностной готовности к риску» $(r s=-0,29)$ и «Шкала поиска ощущений» $(r s=-0,28)$ свидетельствует о том, что молодежь демонстрирует финансовое поведение, для которого характерно накопительство, взаимосвязано с предусмотрительностью и осторожностью. Молодые люди, которые убеждены, что все проблемы можно решить с помощью денег, предпочитают стабильность и упорядоченность в жизнедеятельности.

В результате корреляционного анализа была обнаружена прямая взаимосвязь между показателями «Диагностика уровня личностной готовности к риску» и шкалой «Поиск ощущений» $(\mathrm{rs}=0,48)$. Полученные данные свидетельствуют о том, что склонность к риску взаимосвязана с потребностью в новых впечатлениях, часто экстремального характера. Подобная склонность свойственна для молодых людей в силу их возрастных особенностей.

Следующим этапом анализа данных являлся сравнительный анализ монетарного поведения молодежи в зависимости от пола, возраста и уровня образования при помощи U-критерия Манна-Уитни. В таблице 3 представлены полученные достоверные различия.

В результате сравнительного анализа были получены достоверные различия только в зависимости от пола. Отсутствие различий в зависимости от возраста и уровня образования может свидетельствовать о необходимости и расширения выборки исследования

Таблица 3.

Сравнительный анализ показателей монетарного поведения и склонности к риску в мужской и женской выборке

\begin{tabular}{|l|c|c|c|c|c|c|c|}
\hline \multicolumn{1}{|c|}{ Показатели } & Rank Sum - M & Rank Sum - & U & Z & p-level & Valid N - M & Valid N - $~$ \\
\hline «0беспокоенность деньгами» & 9024 & 18004 & 5196 & $-2,25$ & 0,02 & 87 & 145 \\
\hline «Личностная готовность к риску» & 12639 & 14856 & 4125 & 4,580 & 0,00 & 88 & 146 \\
\hline
\end{tabular}


для окончательных выводов. Как видно из таблицы 3, в женской выборке молодежи показатели по шкалам «Обеспокоенность деньгами» и «Личностная готовность к риску» выше по сравнению с мужской. Это указывает на то, что финансовое поведение девушек, с одной стороны, характеризуется стремлением к накопительству денег, а с другой, сопровождается риском, который может проявляться в различных аспектах, например, риск ради финансового успеха или чрезмерная трата денег. Такой результат может быть обусловлен особенностями культурных представлений о гендерных ролях мужчин и женщин в обществе, например, как представление об обязанности мужчины зарабатывать и обеспечивать семью, которое может детерминировать более осторожное и рациональное отношение с деньгами.

\section{Выво $\Delta$}

Монетарное поведение человека является междисциплинарной проблемой, которая требует интеграции различных направлений науки - психологии, экономики и социологии. Изучение монетарного поведения молодежи с психологической точки зрения позволяет прояснить особенности отношения молодежи к деньгам, выявить паттерны монетарного поведения, изучить стратегии и способы оптимизации денежных установок, направленных на снижение рискованного финансового поведения молодежи, выявить адаптационные механизмы человека в условиях экономической нестабильности. Изучение особенностей взаимосвязи монетарного поведения и жизнестойкости молодежи является актуальной проблемой, которая отражает способность справляться с жизненными обстоятельствами, стремление к преодолению трудностей в финансовой сфере.

По результатам диагностики монетарных аттитюдов, жизнестойкости, уровня личностной готовности к риску и поиска ощущений были количественно и качественно про- анализированы особенности монетарного поведения молодежи во взаимосвязи с компонентами жизнестойкости:

1. Большая часть респондентов демонстрирует критическое отношение к денежным взаимодействиям и финансовым институтам, неготовность к чрезмерным тратам и рисковым вложениям, отсутствие разделения людей по экономическому статусу. Для молодых людей характерна заинтересованность в выполняемой деятельности, удовольствие от неё и ощущение возможности влияния на результат.

2. Молодым людям, для которых характерно отношение к деньгам как к статусу, в большей мере свойственна подверженность стрессовым ситуациям, вызванным отсутствием безопасности и гарантий успеха в какой-либо деятельности, связанной с финансовыми рисками.

3. Молодым людям, которые относятся к деньгам как накопительному ресурсу, свойственны предусмотрительность и осторожность в вопросах обращения с деньгами.

4. Сравнительный анализ мужской и женской выборки молодежи позволил выявить, что для женской выборки, чем для мужской выборки, больше свойственна противоречивость в монетарном поведении. Для девушек характерно как стремление к сохранению и накоплению денег, так и рисковое поведение в отношение денег (чрезмерные траты, спонтанные инвестиции и т.д.).

Дальнейшее изучение различных особенностей монетарного поведения молодежи позволит выявить уровень финансовой культуры в современном обществе и впоследствии разработать рекомендации по формированию эффективного монетарного поведения молодежи, направленные на повышение их финансового благополучия.

\section{ЛИТЕРАТУРА}

1. Баязитова Д.А., Лапшова Т.А. Адаптация опросника монетарных аттитюдов Б. и Т. Клонц на русскоязычной выборке // Петербургский психологический журнал. - 2017. - №19. - С. 112-132.

2. Белехова Г.В., Гордиевская А.Н. Финансовое поведение населения: демографические особенности // Проблемы развития территорий. - 2018. - Вып. 1 (93). - С. 133-150.

3. Богомаз С.А., Баланев Д.Ю. Жизнестойкость как компонент инновационного потенциала человека // Сибирский психологический журнал. - 2009. №32. - C. 23-28.

4. Будакова А.В., Сметанова Ю.В., Богомаз С.А. Психологическая безопасность как условие развития личностного потенциала // Вестник Томского государственного университета. - 2010. - № 338. - С. 156-159.

5. Данченко Е.А., Шлыкова И.А. Проблемы и перспективы повышения финансовой грамотности молодежи // Региональная экономика: теория и практика. - 2018. - T. 16. - № 6. - С. 1041-1051.

6. Джанерьян С.Т., Письменова А.А. Особенности монетарного поведения студентов-психологов в связи с их экономическим статусом // Северо-Кавказский психологический вестник. - 2008. - №1. - С. 83-87.

7. вдокимова А.С. Психолого-экономические аспекты отношения к деньгам студенческой молодежи (на примере обучающихся Забайкальского края) // 
Психология и Психотехника. - 2019. - № 4. - С. 57 - 65.

8. Ильин Е.П. Психология риска / Е.П. Ильин. - СПб: Питер, 2012. - 267 с.

9. Маленко В. И. Статистическое исследование финансового поведения молодежи в контексте отношения к деньгам // Финансовые исследования. - №3. 2013. - C. 68-84.

10. Одинцова М.А. Психология жизнестойкости : учебное пособие / М.А. Одинцова. - М. : ФЛИНТА ; Наука, 2015. - 296 с.

11. Осин Е.Н., Рассказова Е.И. Краткая версия теста жизнестойкости: психометрические характеристики и применение в организационном контексте // Вестник Московского университета. Серия №14. Психология.- 2013. - № 2. - С.147-165.

12. Письменова А.А. Особенности монетарного поведения субъектов в связи с конфликтностью их ценностно-смысловых отношений к деньгам: диссертация ... кандидата психологических наук: 19.00.01 / Письменова Анастасия Александровна; [Место защиты: Юж. федер. ун-т]. - Ростов-на-Дону, 2011. - 315 с.

13. Семенов М.Ю. Психосемантическое исследование понятия «деньги»: гендерный и возрастной аспекты // Омск. науч. вестн. Сер.: Общество. История. Современность. -2009 . - № 3 (78). - С. 124-127.

14. Цукерман М. Шкала поиска ощущений // Альманах психологических тестов. М., 1995, С.187-189.

15. Шабунова А.А. Экономическое поведение населения: теоретические аспекты : препринт / А.А. Шабунова, Г.В. Белехова. - Вологда : ИСЭРТ РАН, 2012 . - 136 с.

16. Klontz B., Britt S.L., Mentzer J., Klontz T. Money Belief and Financial Behaviors: Development of the Klontz Money Script Inventory // The Journal of Financial Therapy. - 2011. - Vol.2.- Is. 1.- P.22.

17. Kobasa S.C., Maddi S.R., Zola M.A. Type A and Hardiness // Journal of Behavioral Medicine. - 1983. - Vol. 6, № 1. - P. $41-51$.

18. Maddi S. Dispositional Hardiness in Health and Effectiveness // Encyclopedia of Mental Health. - San Diego (CA): Academic Press, 1998. - P. 323-335.

19. Maddi S.R., Khoshaba D.M. Hardiness and Mental Health //Journal of Personality Assessment. - 1994. - Vol.63.- N.2.- P.265-274.

20. Schubert R., Brown M., Gysler M., Brachinger H.W. (1999) Financial Decision-Making: Are Women Really More Risk-Averse? // American Economic Review (Papers and Proceedings). - 1999. - Vol. 89 (2). - P. 381-385.

\footnotetext{
( ) Козлова Наталья Викторовна (akme_2003@mail.ru), Ларионова Анастасия Вячеславовна (vktusur@mail.ru), Обуховская Виктория Борисовна (diada1991@gmail.com).

Журнал «Современная наука: актуальные проблемы теории и практики»
}

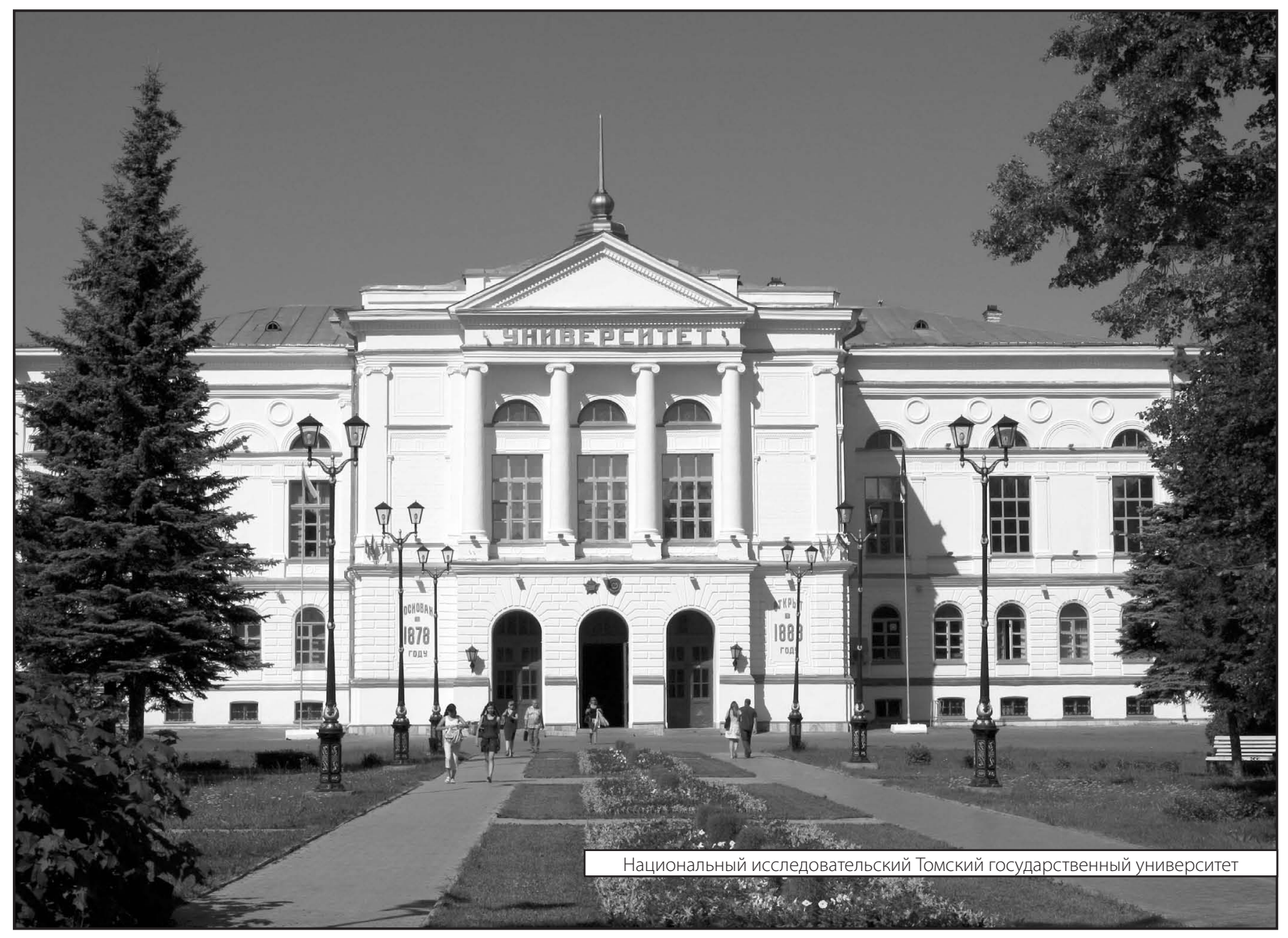

